\title{
Venous lipodermatosclerosis: treatment by fibrinolytic enhancement and elastic compression
}

\author{
K BURNAND, G CLEMENSON, M MORLAND, P E M JARRETT, N L BROWSE
}

\section{Summary and conclusions}

The value of fibrinolytic enhancement with an anabolic steroid (stanozolol) combined with elastic stockings in treating venous lipodermatosclerosis was assessed in a six-month double-blind cross-over trial. Thirty-four legs of 23 patients in whom other treatments had failed were studied. The patients were randomly divided into two groups who were treated with either stanozolol plus elastic stockings or placebo plus elastic stockings for three months, and then vice versa. Treatment with or without stanozolol caused the area of lipodermatosclerosis to decrease, but the rate of healing when patients took stanozolol was double that when they took the placebo, and this was assumed to be biologically important. Stanozolol also reduced the incidence of extravascular fibrin detected in skin biopsy specimens. The elastic stockings with placebo produced significant decreases in leg volume, ankle circumference, and skin thickness.

Stanozolol is valuable in treating intractable lipodermatosclerosis, giving relief of pain and reducing induration, inflammation, tenderness, and pigmentation.

\section{Introduction}

We have described the apparent beneficial effect on venous lipodermatosclerosis (liposclerosis; the changes in the skin and subcutancous changes commonly known as "the postphlebitic leg") of stimulating blood fibrinolytic activity with the anabolic

Department of Surgery, St Thomas's Hospital, London SE1 7EH

K BURNAND, MB, FRCS, senior registrar

G CLEMENSON, research assistant

M MORLAND, BSC, research assistant

N L BROWSE, MD, FRCS, professor of vascular surgery

Department of Surgery, Kingston Hospital, Kingston upon Thames, Surrey

P E M JARRETT, MB, FRCS, consultant surgeon steroid stanozolol (Stromba). ${ }^{1}$ The rationale for this treatment was based on the detection of pericapillary interstitial cuffs of fibrin that, by acting as a diffusion barrier, appeared to be the ultimate cause of venous ulceration."

The results of this pilot study encouraged us to conduct a double-blind cross-over clinical trial to assess the value of stanozolol in the treatment of venous liposclerosis, which is often resistant to other methods of treatment. This trial compared the effect of stanozolol and elastic stockings with the effect of elastic stockings and placebo on the rate of resolution of the area of liposclerosis. It was not a study of the healing of venous ulceration.

\section{Patients and methods}

PATIENT SELECTION

In the pilot study' we selected a group of patients who had been attending our vein clinic for some years and added stanozolol to their treatment, leaving all other treatments unchanged. All these patients had stopped using elastic stockings. In the present trial we wished to study recently referred patients in whom conventional operations had failed. We did not think that it was ethically justifiable to withhold the use of elastic stockings; consequently all patients were prescribed new, properly fitted below-knee Sigvaris elastic stockings, and the trial compared the effect of elastic stockings plus placebo tablets-that is, elastic stockings alone-with the effect of elastic stockings plus stanozolol.

Recently referred patients presenting at the clinic who had had no operations for at least one year and for whom no further operations were contemplated, and who had active liposclerosis but no venous ulceration, were asked to participate in the trial. Informed written consent was obtained from all patients.

\section{PATIENT ASSESSMENT}

A full clinical history was recorded, with particular attention being paid to the patient's age, sex, weight, history of leg disease and deep vein thrombosis, family history, and smoking habits. The state of the leg disease was assessed from the history and the results of the following tests. 
Area of liposclerosis-The edge of the liposclerosis was determined by careful inspection and palpation and marked with a fine felt-tip pen. The enclosed area was measured by placing a piece of standardweight tracing paper over the leg, tracing the marked edge on to the paper, cutting out the enclosed area of paper, weighing it, and converting this result into a measurement of area by using the known weight of $1 \mathrm{~cm}^{2}$ of paper. Every area was calculated by the same observer without knowledge of either the shape or size of the area when measured before, or of the form of treatment. The reliability of the method was tested by measuring 10 areas of liposclerosis on two separate occasions, the observer having no knowledge of the size of the first measurement when determining the second. The mean of the first 10 measurements was $73.3 \mathrm{~cm}^{2}$ and of the second $76.7 \mathrm{~cm}^{2}$, a difference of $4.5^{\prime \prime}$, . Mean circumferences of the two sets of measurements were 32.3 and $33.6 \mathrm{~cm}$ respectively, a difference of $4 "$ "... When individual pairs of measurements were examined the second measurement of area was from $-3^{\prime \prime}$, to $17^{\prime \prime}$. greater than the first (mean

. $7 "$ ".). The second measurement of circumference was from $-7 "$." to $15^{\prime \prime}$. greater than the first (mean $\cdot 6 \cdot 8^{\prime \prime}$.). This technique of measurement thus had an overall accuracy within the range $10^{\prime \prime}$ for both area and circumference, and any change between pairs of measurements or means of groups of measurements orer 20 ". "was regarded as significant.

Clinical photographs were taken in black and white, colour, and infrared with the leg in a standard position to provide a permanent record of the changes that occurred during the trial.

Circumference of the leg was measured at a point $10 \mathrm{~cm}$ above the medial malleolus.

Leg volume was measured by water displacement to a constant level, $45.7 \mathrm{~cm}$ (18 in) above the sole.

Skin thickne's was measured on the medial side of the leg, $10.2 \mathrm{~cm}$ (4 in) above the medial malleolus, using soft-tissue radiography."

Skin biopsy specimc'ns for assessing capillary proliferation and extravascular fibrin deposition ${ }^{4}$ were taken from a point $7.5 \mathrm{~cm}$ above the medial malleolus. The assessor the late Dr I Whimster) had no knowledge of the form of treatment.

Foot vein pressures were measured at rest and during maximal heelraising exercise before and at the end of the trial.

General blood studies such as haemoglobin concentration, packed cell volume, plasma protein concentrations, and liver-function tests were performed by the usual pathology services.

Special blood test-Blood was taken between (19)30 and 1030 by clean vein puncture without congestion, in the fasting state, for measurement of plasma fibrinogen concentration by the clot-weight method" and dilute blood clot lysis time (DBCLT)."

\section{PLAN OF TRIAL}

The above tests were performed before the trial began. The patients were then fitted with Sigvaris elastic stockings, which were renewed at any time if they appeared to be getting slack. Randomised allocation cards were used to determine the order of treatment, and each patient was given either stanozolol $5 \mathrm{mg}$ twice daily or placebo twice daily for three months; the treatment was reversed during the second three months. A simple clinical assessment was performed at six weeks, as were blood tests. All the initial tests were repeated at three months, when the drugs were crossed over. The simple clinical assessment and blood studies were repeated at 18 weeks. All tests, and usually the studies of foot vein pressure, were repeated at the end of six months.

Analysis of results-Results were analysed in groups using paired and unpaired Student's $t$ tests.

\section{Results}

Out of 23 patients (10 women and 13 men) who entered and completed the trial, nine were given placebo first and 14 stanozolol. This d:ference occurred because of the method of allocation but does not affect the results because the drugs were crossed over at three months. The mean age of the patients was 57 years (range 3871). This was also the mean age of both sexes when considered separately. The average weight of the 23 patients was $79.4 \mathrm{~kg}(175 \mathrm{lb})$, range $68 \cdot 0-98 \cdot 4 \mathrm{~kg}(150-217 \mathrm{lb})$. Eight patients were smokers.

Seven patients had a definite history of deep vein thrombosis, 17 a family history of varicose veins, and three a history of intermittent claudication but no symptoms of arterial ischaemia at the time of the trial. All patients had varicose veins, which they reported had been present for a mean of 22 years (range 6-50). The symptoms and signs of liposclerosis (eczema, pigmentation, pain, and induration) had been present for a mean of 11 years (range 2-25). In 12 patients the disease was unilateral and in 11 bilateral. No patients had open ulceration at any time during the trial. Extensive varicose vein surgery such as high saphenous vein ligation, saphenous vein stripping, communicating vein ligation, and various forms of injection sclerotherapy had been performed on all the legs with liposclerosis over many years but not within one year before the trial.

Four of the nine patients who began with placebo and elastic stockings had unilateral disease and five had bilateral disease, giving 14 legs for analysis; and eight of the 14 patients who began with stanozolol and elastic stockings had unilateral disease and six had bilateral disease, giving 20 legs for analysis. Thus 34 areas of liposclerosis were studied during the six-month trial.

\section{LIPOSCLEROSIS}

Figure 1 shows the changes in the mean areas of liposclerosis in the two groups. Figure 2 combines these results, ignoring the possibility that the response in the second three months might have been affected by the response in the first three months. Figure 3 compares the means of the areas that were healed by the two forms of treatment.

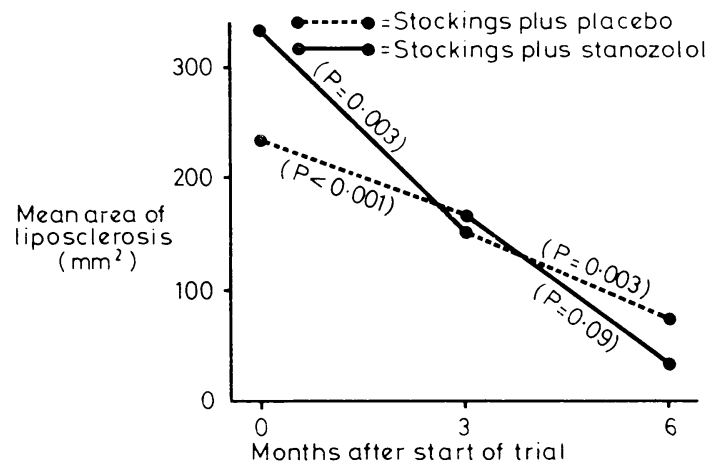

FIG 1-Mean areas of liposclerusis before treatment, at crossover point, and at end of treatment in the two groups of patients. P values give significance of changes (Student's $t$ test).

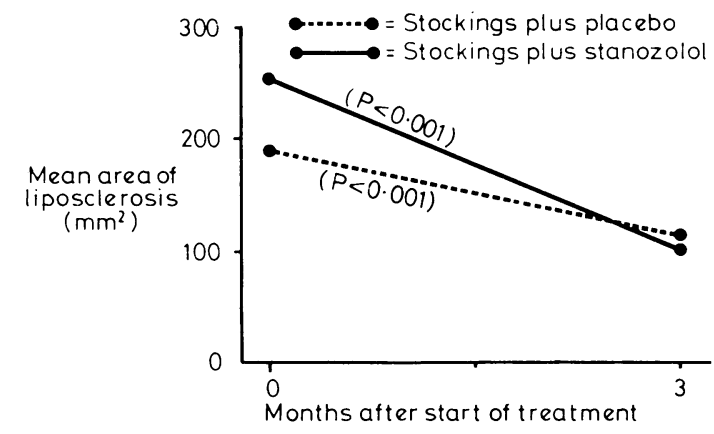

FIG 2-Mean areas of liposclerosis before and after treatment. The two groups of patients taking placebo and the two taking stanozolol in fig 1 have been combined. $P$ values give significance of changes (Student's $t$ test).

The mean area of healing during treatment with stanozolol and elastic stockings was $155 \mathrm{~mm}^{2}$ (SE of mean 40) compared with $78 \mathrm{~mm}^{2}$ (SE of mean 15) during treatment with placebo and elastic stockings. An unpaired $t$ test showed that the probability that this was not a chance difference was $90^{\circ}{ }^{\prime}$. This is not usually regarded as a statistically significant difference, but we believe that this difference was biologically important. The beneficial effect of the stanozolol was blurred by using elastic stockings, which were effective in their own right.

The increased rate of healing with stanozolol occurred whether it was given in the first or second three months of treatment (fig 1). 
In both groups of patients the area that healed doubled when they were taking stanozolol $\left(173 \mathrm{~mm}^{2}\right.$ compared with $83 \mathrm{~mm}^{2}$ and $130 \mathrm{~mm}^{2}$ compared with $72 \mathrm{~mm}^{2}$ respectively). The changes in the areas of liposclerosis for both forms of treatment at three and six months were significant when both groups were considered separately (fig 1) or together (fig 2).

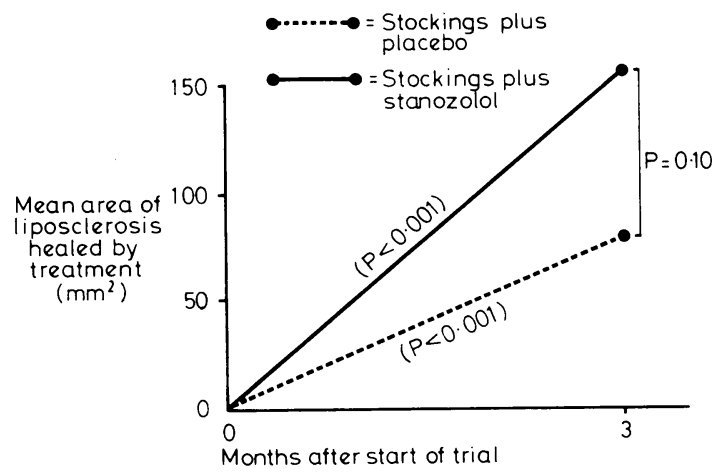

FIG 3-Mean areas of liposclerosis healed by two forms of treatment. P values give significance of changes (Student's $t$ test).

Patients were asked at each visit whether they thought that the pain, heat, colour, and hardness of the liposclerosis had improved over the previous six weeks. After three months' treatment with placebo and elastic stockings six of the nine patients thought that their legs were better. After the second three months, when they took stanozolol, all considered that there had been further improvement. Eleven of the 14 patients who began treatment with stanozolol thought that their legs had improved at the end of three months; but after three months on placebo only nine thought that there had been further improvement. Almost all the patients thus believed that treatment had improved their liposclerosis, but most could not detect any difference between their responses to placebo and stanozolol even though the mean area of healing was greater when they were taking stanozolol.

\section{LEG DIMENSIONS}

Figure 4 shows the changes in mean leg volume, ankle circumference, and skin thickness. When patients were treated with placebo plus elastic stockings their leg volumes fell significantly, whereas leg volumes increased (though not significantly) during treatment with stanozolol plus elastic stockings.

Ankle circumference increased significantly in those patients who

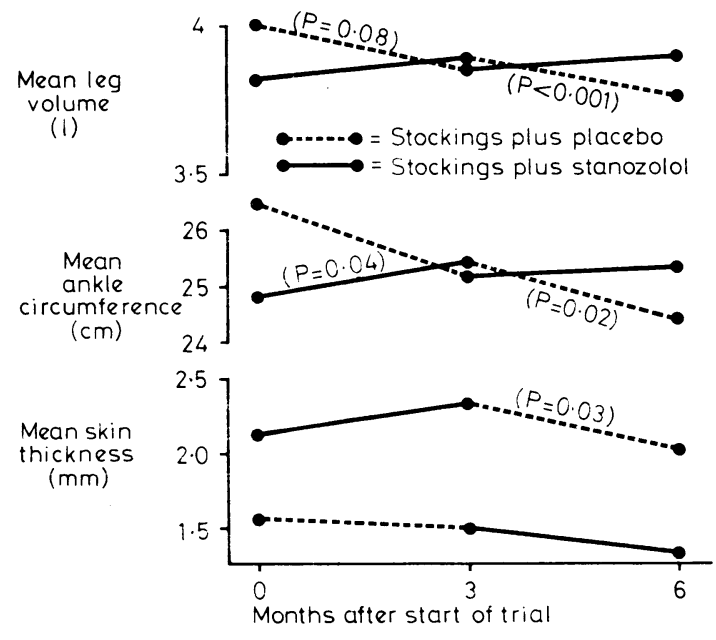

FIG 4-Effect of elastic compression plus stanozolol or placebo on mean leg volume, ankle circumference, and skin thickness in the two groups of patients. P values give significance of changes (Student's $t$ test. began treatment with stanozolol plus elastic stockings and decreased significantly when they changed to placebo and elastic stockings. There was a similar, but non-significant, reduction in ankle circumference in the patients who began treatment with placebo plus elastic stockings, but there was no change when this group changed to stanozolol.

The skin $10 \cdot 2 \mathrm{~cm}(4$ in) above the medial malleolus of the patients who were given stanozolol first became thicker but then showed a significant thinning during treatment with placebo and elastic stockings. The skin thickness of the patients who took placebo first and then stanozolol showed no significant change.

\section{BLOOD CHANGES}

The haernoglobin and plasma protein concentrations showed no significant changes throughout the trial. The only liver-function test result to change during treatment with stanozolol was serum aspartate transaminase (serum AST; SGOT) activity. In 15 of the 23 patients it did not alter; in five it rose from a mean of 50 units to a mean of 78 units (range 70-90; normal range 25-65); and in three it rose to 115,125 , and 140 units respectively but fell to normal levels within one month of changing to placebo. Three patients showed a slight increase in their serum creatinine concentrations.

Mean plasma fibrinogen concentration fell significantly during treatment with stanozolol plus elastic stockings and rose significantly when stanozolol was stopped (fig 5). The group that took placebo

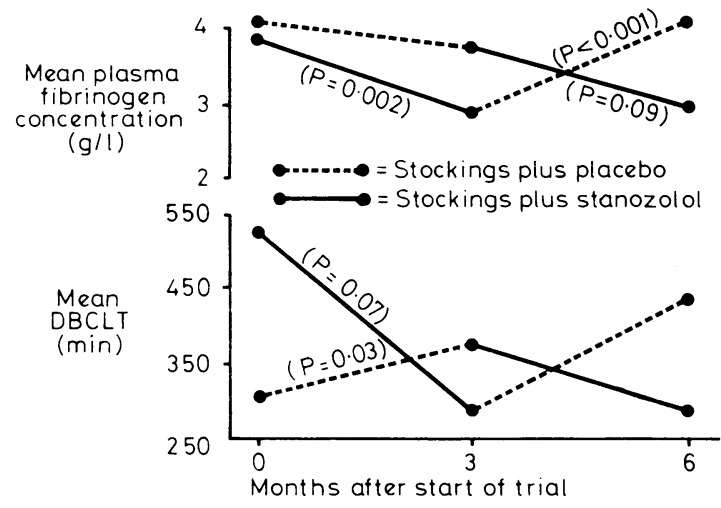

FIG 5-Effect of stanozolol plus clastic stockings and placebo plus elastic stockings on mean plasma fibrinogen concentration and mean dilute blood clot lysis time (DBCLT). P values give significance of changes (Student's $t$ test).

Concirsion: SI to traditional units-Plasma fibrinogen concentration: $1 \mathrm{~g} / 1 \quad 100 \mathrm{mg} / 100 \mathrm{ml}$.

for the first three months showed no change in mean plasma fibrinogen concentration during this time. Their mean plasma fibrinogen concentration fill during the second three months, when they were taking stanozolol, but this fall did not reach significance $(P=0 \cdot 09)$.

The mean DBCLT fell significantly for the first three months in the patients who began treatment with stanozolol and rose significantly during this time in the patients who began treatment with placebo. The other changes in DBCLT (fig 5) were in the expected direction but did not achieve significance. This was almost certainly because of the wide natural variations in DBCI.T and the small numbers of patients studied.

\section{SKIN HISTOLOGY}

The biopsy specimens were studied to assess the number of skin capillaries and the incidence of extravascular fibrin. Biopsies were performed before treatment and at three and six months on 34 legs.

Capillary proliferation was divided into four grades of severitynormal, mild, moderate, and severe-and converted into numerical scores $(0,1,2$, and 3 respectively). The mean capillary proliferation scores for each group of patients whether receiving stanozolol or placebo decreased steadily throughout the trial (fig 6). Over the whole six months the mean score of all patients fell from $2 \cdot 7$ to $2 \cdot 2$. 


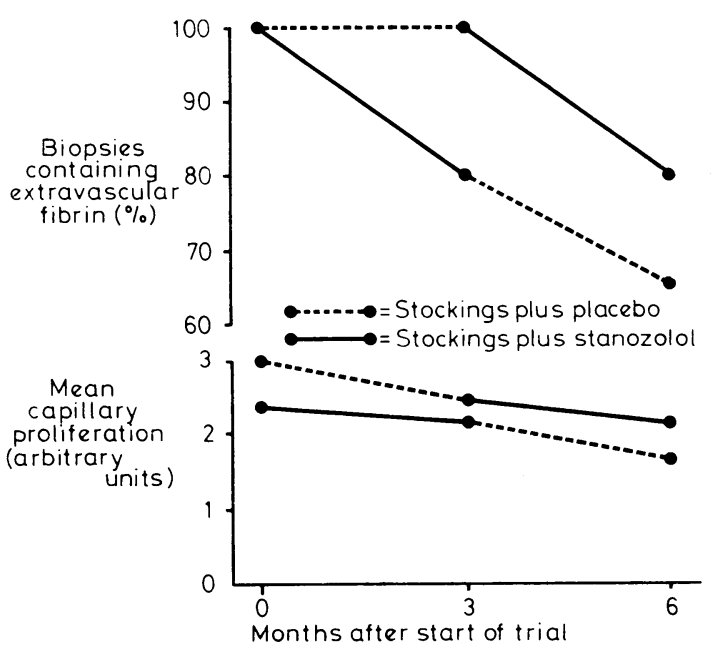

FIG 6-Effect of stanozolol plus elastic stockings and placebo plus elastic stockings on incidence of extravascular fibrin and number of dermal capillary loops (as mean proliferation score) in skin biopsy specimens.

The phosphotungistic acid haemotoxylin stain for fibrin was not used on the biopsy specimens taken at the beginning of the trial, so only 26 sets of specimens were stained: 11 from patients who began treatment with placebo, and 15 from patients who began treatment with stanozolol. All the specimens taken at the start of the trial contained fibrin. There was no change after three months in the patients who began treatment with placebo plus elastic stockings, but three months later, after these patients had taken stanozolol, two specimens showed no extravascular fibrin, giving a reduction of 18 ". for the whole group (fig 6). Three of the biopsy specimens from the 14 patients who had taken stanozolol for the first three months showed no extravascular fibrin, a $21^{\prime \prime}$ "reduction for the whole group. After the next three months of placebo plus elastic stockings another two specimens contained no fibrin, giving an overall change of $30^{\prime \prime}$. These results are shown in fig 6 as percentages because the numbers are too small for statistical analysis, but they suggest that stanozolol does reduce the quantity of extravascular fibrin in $10-2()^{\prime \prime}$," of patients.

\section{FOOT VEIN PRESSURES}

The mean maximum reduction in foot vein pressure during exercise (expressed as a percentage of the resting pressure) for all legs before treatment was $17^{\prime \prime}$. . The normal reduction is between $60^{\prime \prime}$ " and $80^{\prime \prime}$, . After six months of wearing elastic stockings with and without stanozolol the mean maximum reduction in pressure during exercise was 21 "..

\section{COMPLICATIONS OF TREATMENT}

The changes in serum AST activity and serum creatinine concentration during treatment with stanozolol were minor and not associated with any clinical manifestations of hepatotoxicity. All tests gave normal results after stanozolol was stopped, and in some patients the results became normal even when stanozolol was continued. Three patients complained of headaches, and two women developed light, irregular periods when taking stanozolol. Some patients believed that they had put on weight when taking stanozolol, but our measurements of their weight did not confirm this. The mean weight of all patients before taking stanozolol was $79.5 \mathrm{~kg}(175 \mathrm{lb})$, and after three months of taking stanozolol it was $78.5 \mathrm{~kg}(173 \mathrm{lb})$.

\section{Discussion}

The changes in the skin and subcutaneous tissues of the leg associated with longstanding venous hypertension, often postphlebitic in origin, may be difficult to treat. W'hen there is a clearly definable cause, such as a cluster of incompetent communicating veins, operations can produce an effective cure, but in some patients there is extensive irreparable deep vein damage and operations are ineffective. - Our studies suggest that venous liposclerosis, and eventually venous ulceration, are caused by deposition of an impermeable fibrin cuff around the dermal capillaries, caused by prolonged venous hypertension and exacerbated by a deficiency of blood and tissue fibrinolytic activity. 289

As we had to treat a group of patients in whom conventional treatment had failed we thought it reasonable to assess the effect of stimulating the fibrinolytic system with stanozolol. A pilot study ${ }^{1}$ indicated that this would be worth while, and we set up a double-blind cross-over trial to test this drug.

The major problem was assessing the liposclerosis. Measuring an indurated tender area of skin and subcutaneous tissue is difficult. We chose our method of measurement because it was simple, direct, and reproducible to within $10^{\prime \prime}{ }^{\prime .}$. Other methods of assessing healing, such as percentage change or those entailing calculations of area and perimeter length, appeared to offer no advantages.

To gain as much information as possible about the leg we measured leg circumference, leg volume, skin thickness, and foot vein pressure and assessed skin histology (for capillary proliferation and extravascular fibrin). These additional measurements were particularly relevant to the mechanical effects of the elastic stockings, which we felt ethically obliged to include in our treatment regimen.

Stanozolol prolonged the mean DBCLT and reduced mean plasma fibrinogen concentrations; blood fibrinolysis was, therefore, enhanced. This confirms the results of other studies of stanozolol. ${ }^{10}$ 1:2 Unfortunately stanozolol takes four weeks to produce this effect, and after stopping treatment the effect takes four weeks to wear off. This makes interpretation of the results in the second three-month period for those who took stanozolol in the first three months difficult, because for at least one month of their treatment with placebo their blood fibrinolysis was still partially enhanced. Without this "hangover" effect some of the results that only just reached significance might have been more significant.

Both placebo plus elastic stockings and stanozolol plus elastic stockings produced a highly significant reduction in the mean area of liposclerosis $(P=0.001)$. The mean rate of healing was twice as great when the patients were taking stanozolol, but the statistical probability that this difference was caused by the drug was only $90^{\prime},$. . Nevertheless, we believe that this is a biologically important difference because of the other changes that occurred when the patients took stanozolol such as rapid alleviation of pain and tenderness, and particularly the loss of skin pigmentation, which did not occur in the period of treatment with placebo. These differences were impossible to quantify, but, since the mean healing rate doubled (figs 1, 2, and 3), we are certain that stanozolol had a real, significant, and independent effect, which was also apparent in our pilot study in which elastic stockings were not used.' Our present study did not include a group of subjects who were not treated because all the patients had been specially referred to our clinic from other centres because their liposclerosis was deteriorating or had failed to respond to other treatment. Spontaneous improvement was, therefore, unlikely, and we thought that a "non-treatment" group was unjustifiable.

By causing minor fluid retention stanozolol opposed the effect of the clastic stockings in reducing mean leg volume and circumference but not to the extent that the mean leg volume increased. Placebo plus elastic stockings-that is, clastıc stockings alone-caused a significant reduction in mean leg volume.

All biopsies showed some capillary proliferation. This was not altered by stanozolol but did reduce over the six months of the trial, presumably as a result of compression caused by the stockings. All pretreatment biopsy specimens contained extravascular fibrin. Placebo and elastic stockings given for the first three months of the trial did not alter the quantity of fibrin in the specimens. Stanozolol plus elastic stockings reduced the number of specimens containing fibrin by about $20^{\prime \prime}$ " in both 
groups. There was also a reduction in the number of biopsy specimens containing fibrin taken from those patients treated with placebo plus clastic stockings for the second three months of the trial, but whether this was a hangover effect from the previous three months of taking stanozolol or an effect caused by the clastic stockings is impossible to say. It is unlikely to have been caused by the stockings because it did not occur in those who began treatment with placebo and stockings.

The mean exercising foot rein pressures were unaltered by the trial. This confirmed that the treatment caused no fundamental change in the efficiency of the calf muscle pump, though pump function was cortainly changed while the elastic stockings were heing worn.":

The side effects of treatment were slight and did not cause anyone to stop treatment. Liver-function test abnormalities were minor and resolved spontancously.

All but one patient believed that their legs had improved but were unable to differentiate between the effect of placebo and that of stanozolol except for the effect on pain. The burning discomfort that some patients suffered in the area of liposclerosis eased within three to four weeks after beginning stanozolol. All patients wanted to continue treatment with stanozolol after the trial had ended. The long-term results have been encouraging and will be the subject of a further report. In almost every patient the induration has disappeared after six to nine months of treatment, and in many the brown pigmentation has also regressed. We have stopped giving stanozolol after 12 months of treatment, and so far the legs have remained healthy with the use of good elastic stockings.

Stanozolol is a useful addition to the treatment of venous liposclerosis, but we advise that it is used only in intractable cases in which other methods of treatment have failed. Stanozolol takes at least three months to produce a worthwhile response and nine to 12 months to achicre its maximum effect. During this time the patient should be observed carefully for evidence of excessive water retention or masculinisation, and liverfunction tests and measurements of plasma fibrinogen concentrations conducted regularly. Stanozolol may be assumed to be enhancing fibrinolysis if the plasma fibrinogen concentration falls, hut administration should be stopped if AST activity rises above 120 units.

The clinical response of liposclerosis to fibrinolytic enhancement and the histological eridence of a reduction in the quantity of extravascular fibrin in the skin of some patients after only three months of treatment with stanozolol support our hypotheses on the actiology of venous ulceration. The results of this trial have encouraged us to look for other drugs that are more effective long-term stimulators of blood, interstitial fluid, and tissuc fibrinolysis.

We are grateful to Winthrop-Sterling and the trustees of St Thomas's Hospital endowment fund for financial help.

Requests for reprints should be addressed to Professor N L Browse.

\section{References}

Browse NI. Jarrett PEM, Morland M, Burnand KG. Treatment of liposclerosis of the leg by fibrinolytic enhancement, a preliminary report. Br Med $71977 ; 3:+3 \cdot 4-5$

Browse NI, Burnand KG. In: Bergan J, Yao J, eds. Venous problems. Chicago: Year Book Medical Publishers, 1978:395-404.

Black .1. A modified radiographic method for measuring skin thickness. Br 7 Dirmatol 1969;81:661-6.

'Burnand KG, Clemenson (3, Whimster I, Browse NL. Extravascular fibrin deposition in response to venous hypertension. Br.F Surg 1976; $63: 600$.

Ingram ( $I$ IC. Determination of plasma fibrinogen by clot weight method. 7 Bicithm 1952;51:583-5.

"Farnley (iR, Balmforth GV, Fearnley E. Evidence of a diurnal fibrinolytic rhythm: with a simple method of measuring natural fibrinolysis. Clin Sii $1957 ; \mathbf{1 6}: 645-50$.

Burnand KG, Lea TM, O'Donnell T, Browse NL. Relationship between postphlebitic changes in the deep vein and results of surgical treatment of venous ulcers. Lancet 1976;1:936-8.

Browse NL, Gray L, Jarrett PEM, Morland M. Blood and vein wall fibrinolytic activity in health and vascular discase. Br Med f 1977;1:47881.

9 Jarrett PI:M, Burnand KG, Morland M, Browse NL. Fibrinolysis and fat necrosis in the lower leg. Br.7 Surg 1976;63:157.

") Davidson Jl: Lockhead M, MCL onald GA, MCNichol GP. Fibrinolytic enhancement by stanozolol. A double blind trial. Br.F Hacmatol 1972; $22: 5+3-59$.

"Jarrett Pl:M, Morland M, Browse NL. Idiopathic recurrent superficial thrombophlebitis; treatment with fibrinolytic enhancement. Br Med $\mathcal{F}$ $1977 ; 2: 933-4$.

12 Jarrett Pl:M, Morland M, Browse NL. Treatment of Raynaud's phenomenon by fibrinolytic enhancement. Br Med f 1978;2:523-5.

1:3 Fentem PH, Goddard M, Gooden BA, Yeung C.K. Control of distension of varicose veins achicved by leg bandages as used after injection sclerotherapy. Br Mid 7 1976;2:725-7.

(Accoptid 17 ()itober 1979)
ONE HUNDRED YEARS AGO In the rear $15 \%$, application was made by the Home ()ffice to the Local (iovernment Board to allow onc of the inspectors of their medical department to inquire into the eauses of a considerable prevalence of tuphoid fever amongst the boys on board the Cormicall, specially with regard to the allegation that their health was affected by the outflow of metropolitan sewage at Barking and Crossness. Mr Radeliffe was commissioned to make the inquiry, which was of a desultory kind, being made in the intervals of more pressing work. Nothing came of it except some valuable observations which will be found chronicled in volume il of the Jot R.NAL for 1878 , pages 934 and 935 ) on the vexed question of the pollution of the Thames. $\mathrm{Mr}$ Radeliffe found the registration of sickness and death on board the ship to be so defective as to hamper his inquiry seriously, and in the end nothing definite was arrived at as to the circumstances of the outhreak. It is just possible, from what has now transpired, that the outbreak of "typhoid iever," which Mr Radeliffe could make nothing of, was, in fact, an outbreak of trichinosis, for the one disease may easily be mistaken for the other. In fact, the enteric irritation, the loss of appetite, diarrhoca, the irritation and pain in muscles, the ferer, sweating, anasarca, the diminished secretion of urine. combined with continued sleeplessness, produce a condition of the blood in trichinous patients which those who have well observed it have termed typhoid- or typhus-like. A further series of cases of "twphoid ferer" having occurred on board the Cormall last autumn, application was again made by the Home (Office for a reinspection of the ship by the medical department of the Local (jovernment Board. This request was complied with, and $\mathrm{Mr}$ W H Power was instructed to make the inquiry. The records of sickness have apparently been improved since Mr Radcliffe visited the ship; for Mr Power, on commencing his investigation, was at once struck with certain symptoms and clinical facts which hardly accorded with the cases being typhoid ferer; and his suspicions were aroused that he was dealing with an outbreak of trichinosis. With the view of clearing up this point, it was necessary to exhume the body of the only boy whose attack was fatal; and the sanction of the Secretary of State having been obtained, this was done, and a post mortem examination made of the remains. Clear eridence was then obtained that the boy had not died of typhoid fever, as supposed, but of trichinosis, and Mr Power is now working out the symptoms of the other boys whose attacks were not fatil. There cann of course, be no doubt that the outbreak has been caused by the eating of trichinous pork of some kind or other; but until Mr Power's final report is publicly issued, it seems premature to brand any particular description of pork as concerned in the outbreak. The only previous outbreak of trichinosis in this country that has been recognised, that at Wokington in April 1871, was caused by eating the flesh of a home-fed pig. It might have been thought that, of all ways of killing the trichina, the prolonged and continuous boiling, which is the universal mode of preparing pork on board-ship, was the most effective. It may perhaps turn out that, on a particular occasion, the pork was not boiled sufficiently long, and was underdone. Consumers of pork need not, however, entertain any forchoding as to our immunity from trichinosis being a thing of the past. All that they have to be careful of is, that the food is properly and thoroughly cooked. (British Medical fournal, 1880.) 